\title{
Deep Improvement of Heterogeneous Subsoils under Urban Conditions
}

\author{
Jung Stefan \\ Dr. Jung + Lang Ingenieure GmbH \\ Europaallee 17, 66113 Saarbruecken, Germany \\ jung@JL-ingenieure.com
}

\section{Extended Abstract}

In the city of Bonn in Germany an urban waste area had to be prepared for construction of a new commercial center. The underground consisted of heterogeneous backfilling until a depth of $25 \mathrm{~m}$ containing different types of soils and waste in an unregular and uncompacted layering. Geotechnical investigations indicated significant voids until depth of $6 \mathrm{~m}$ that were at risk of uncontrolled sagging. Voids of the deposit material were filled with explosive gas (methane) due to decomposition of organic substances. From the geotechnical and environmental point of view the site preparation was found as highly hazardous.

Surrounding properties such as streets, railways and buildings were situated immediately or very close to the construction line and had to be protected against emissions of vibrations, dust and noise as well as fire and health risks caused by uncontrolled escape of explosive gas.

The soil improvement was planned in several varieties under consideration of all technical and economic aspects. It was carried out for the full construction area by falling weight deep compaction. Stone columns were statically designed using the analytical calculation method of Priebe that had to be modified for large column diameters and heterogeneous soil conditions. The arc action behavior between column heads was investigated and verified by additional numerical simulations (FEM).

The stone columns were installed until depth of more than $6 \mathrm{~m}$ with a compaction energy of $400 \mathrm{tm}$ (20t falling weight, 20m falling height). The columns were placed regularly in a manner of a grid, whereas grid distance related to future foundation loads according to the analytical design. Columns were carried out by using coarse concrete recycling stones with a range of grain size between $60-200 \mathrm{~mm}$. The coarse materials ensured a high bearing capacity for vertical foundation loads as well as a vertical drainage system for upcoming explosive gas due to their high permeability.

The falling weight installation process of the columns was accompanied by excessive vibration emissions that were noticed significantly at surrounding properties and residents. Technical solutions such as damping trenches were needed to constrain vibrations and were designed by analytical calculations under consideration of practical experiences. The real vibrations were observed by measurements during the complete installation works in order to adjust vibration energy target-oriented.

Upcoming explosive gas through the columns was collected in a horizontal bearing stratum above the column heads, guided by gas drainage system and disposed by flare stacks. The new building and underground installations were protected additionally by specific sealing.

After the deep soil improvement with gas drainage the waste site was prepared for conventional foundation of the new structures with single- and strip foundations and geotechnical as well as environmental risks became acceptable.

\section{References}

[1] "Vibro Replacement Design Criteria and Quality Control," ASTM Publication STP 1089, Deep Foundation Improvements: Design, Construction, and Testing, 1991.

[2] H. J. Priebe, M. P. Moseley, "Vibro techniques," in Ground Improvement, Blackie Academic \& Professional, Glasgow, 1993.

[3] K. Kirsch, F. Kirsch, "Ground improvement by deep vibratory methods," Spon Press, 2010.

[4] M. Achmus et al, "Building vibrations due to deep vibro processes," in $7^{\text {th }}$ Conference on Ground Improbvement Techniques, Seoul, 2010. 